\title{
Perioperative echocardiography-guided hemodynamic therapy in high-risk patients: a practical expert approach of hemodynamically focused echocardiography
}

\author{
R. F. Trauzeddel ${ }^{1} \cdot$ M. Ertmer ${ }^{2} \cdot$ M. Nordine ${ }^{1} \cdot$ H. V. Groesdonk ${ }^{3} \cdot$ G. Michels ${ }^{4} \cdot$ R. Pfister ${ }^{4} \cdot$ D. Reuter $^{5}$. \\ T. W. L. Scheeren ${ }^{6} \cdot$ C. Berger ${ }^{1} \cdot$ S. Treskatsch ${ }^{1}$
}

Received: 17 December 2019 / Accepted: 19 May 2020 / Published online: 26 May 2020

(c) The Author(s) 2020

\begin{abstract}
The number of high-risk patients undergoing surgery is growing. To maintain adequate hemodynamic functioning as well as oxygen delivery to the vital organs $\left(\mathrm{DO}_{2}\right)$ amongst this patient population, a rapid assessment of cardiac functioning is essential for the anesthesiologist. Pinpointing any underlying cardiovascular pathophysiology can be decisive to guide interventions in the intraoperative setting. Various techniques are available to monitor the hemodynamic status of the patient, however due to intrinsic limitations, many of these methods may not be able to directly identify the underlying cause of cardiovascular impairment. Hemodynamic focused echocardiography, as a rapid diagnostic method, offers an excellent opportunity to examine signs of filling impairment, cardiac preload, myocardial contractility and the function of the heart valves. We thus propose a 6-step-echocardiographic approach to assess high-risk patients in order to improve and maintain perioperative $\mathrm{DO}_{2}$. The summary of all echocardiographic based findings allows a differentiated assessment of the patient's cardiovascular function and can thus help guide a (patho)physiological-orientated and individualized hemodynamic therapy.
\end{abstract}

Keywords Perioperative $\cdot$ Echocardiography $\cdot$ Hemodynamic optimization $\cdot$ Monitoring

S. Treskatsch

sascha.treskatsch@charite.de

R. F. Trauzeddel

ralf-felix.trauzeddel@charite.de

M. Ertmer

martin.ertmer@charite.de

M. Nordine

michael.nordine@charite.de

H. V. Groesdonk

Heinrich.Groesdonk@helios-gesundheit.de

G. Michels

guido.michels@uk-koeln.de

R. Pfister

roman.pfister@uk-koeln.de

D. Reuter

Daniel.reuter@med.uni-rostock.de

T. W. L. Scheeren

t.w.l.scheeren@umcg.nl

C. Berger

christian.berger@charite.de
1 Department of Anesthesiology and Intensive Care Medicine, Campus Benjamin Franklin, Charité - Universitätsmedizin Berlin, Corporate Member of Freie Universität Berlin, Humboldt-Universität zu Berlin, and Berlin Institute of Health, Berlin, Germany

2 Department of Anesthesiology, Unfallkrankenhaus Berlin, Berlin, Germany

3 Department of Interdisciplinary Intensive Care Medicine and Intermediate Care, Helios Hospital Erfurt, Erfurt, Germany

4 Department of Internal Medicine III, Heart Center, Faculty of Medicine and University Hospital Cologne, University of Cologne, Cologne, Germany

5 Department of Anesthesiology and Intensive Care Medicine, University of Rostock, Rostock, Germany

6 Department of Anesthesiology, University Medical Center Groningen, University of Groningen, Groningen, Netherlands 


$\begin{array}{ll}\text { Abbreviations } \\ \text { 4C } & \text { 4-Chamber view } \\ \text { AS } & \text { Aortic stenosis } \\ \text { AV } & \text { Aortic valve } \\ \text { CO } & \text { Cardiac output } \\ \text { DO2 } & \text { Oxygen delivery } \\ \text { FAST } & \text { Focused Assessment with Sonography in } \\ & \text { Trauma } \\ \text { HFmrEF } & \text { Heart failure with mid-range ejection fraction } \\ \text { HFpEF } & \text { Heart failure with preserved ejection fraction } \\ \text { HFreF } & \text { Heart failure with reduced ejection fraction } \\ \text { IAS } & \text { Interatrial septum } \\ \text { ICU } & \text { Intensive Care Unit } \\ \text { IVC } & \text { Inferior vena cava } \\ \text { LA } & \text { Left atrium } \\ \text { LV } & \text { Left ventricle } \\ \text { LVEDD } & \text { End-diastolic left ventricular diameter } \\ \text { LVEF } & \text { Left ventricular ejection fraction } \\ \text { LVOT } & \text { Left ventricular outflow tract } \\ \text { ME } & \text { Midesophageal } \\ \text { PLAX } & \text { Parasternal long axis } \\ \text { PPV } & \text { Pulse pressure variation } \\ \text { PSAX } & \text { Parasternal short axis } \\ \text { RV } & \text { Right ventricle } \\ \text { S4C } & \text { Subcostal 4-chamber view } \\ \text { SAX } & \text { Short axis } \\ \text { SIVC } & \text { Subcostal view of the inferior vena cava } \\ \text { SIVC-DI } & \text { SIVC-Distensibility index } \\ \text { SV } & \text { Stroke volume } \\ \text { SVC } & \text { Superior vena cava } \\ \text { SVC-CI } & \text { SVC collapse index } \\ \text { TAPSE } & \text { Tricuspid Annular Plane Systolic Excursion } \\ \text { TEE } & \text { Transesophageal echocardiography } \\ \text { TGSAX } & \text { Transgastric short axis } \\ \text { TTE } & \text { Transthoracic echocardiography } \\ \text { VTI } & \text { Velocity time integral } \\ & \end{array}$

\section{Background}

Adequate oxygen delivery $\left(\mathrm{DO}_{2}\right)$ is of utmost importance for the maintenance of homeostatic organ function and is significantly dependent upon cardiac stroke volume (SV). Determinants of SV are pre- and afterload, intrinsic contractility, heart rate/rhythm as well as cardiac valve function. It has long been known that a critically reduced $\mathrm{DO}_{2}$ can worsen the perioperative outcome by promoting a systemic inflammatory response (SIRS) and organ dysfunction through hypoperfusion [1, 2]. High-risk patients, with or without pre-existing cardiac disease, may have an increased risk for a compromised SV during the perioperative period and demand a specific level of monitoring [3].
Extensive research has shown that perioperative hemodynamic optimization amongst high-risk patients can reduce post-operative complications [4-10]. Various advancedand mostly invasive-hemodynamic monitoring techniques are available in daily clinical practice [11], however, particular clinical circumstances (e.g. arrhythmia, right ventricular dysfunction, lung-protective or one-sided ventilation) limit the reliability of some of these techniques, e.g. $\mathrm{SV}$ measurement, and pulse pressure variation (PPV). The main advantage of these hemodynamic monitoring techniques is the ability to measure important surrogate variables for cardiovascular function over time. This allows for a continuous evaluation of the effect of therapeutic interventions such as fluid substitution or vasoactive medication administration. The main disadvantages of these monitoring techniques, however, is the inability to directly assess overall intravascular fluid status and the cardiovascular cause of a reduced $\mathrm{DO}_{2}$ [12]. For example, a reduced $\mathrm{SV}$ can be caused by hypovolemia, reduced LV systolic function or pericardial tamponade, all of which require differing intervention strategies in order to maintain hemodynamic stability. Furthermore it has been specifically shown that arterial blood pressure and SV do not have a linear relationship with one another [13], thereby negating an exclusive reliance upon arterial blood pressure as an indicator of $\mathrm{DO}_{2}$.

In this context, transthoracic (TTE) and transesophageal (TEE) echocardiography are becoming increasingly essential for the anesthesiologist [14-16]. Echocardiographyguided hemodynamic examination provides a real-time pathophysiological-oriented approach, which allows for the evaluation of both left and right cardiac function and the relative circulatory state [17]. It has been shown that use of an echocardiography-based hemodynamic optimization protocol improved outcomes amongst septic patients in an ICU (Intensive Care Unit) setting [18-20]. In hemodynamically unstable patients unresponsive to initial treatment, there is a class I indication for performing a timely echocardiographic examination in order to accurately assess and implement interventions aimed at maintaining hemodynamic stability [21-25]. Interestingly, it has been shown that a hemodynamically focused echocardiography seems to be sufficient in guiding cardiovascular therapy [25-29]. Nevertheless, experience is essential in order to adequately interpret and evaluate TTE/TEE findings. Therefore, a standardized curricular training based on pathophysiological hemodynamic issues should be implemented in order to uphold quality practice standards [30], as well as available standard algorithms for performing TTE/TEE [31]. There is evidence to suggest, however, that after an initial 2-h TTE training course, anesthesiologist without prior experience in echocardiography could obtain adequate image via TTE compared with cardiothoracic anesthesiologist fellows [32], yet interpretation of the clinical scenario and the necessary interventions needed 
require a certain level of expertise. "Focused examiners" have the responsibility to seek expert help whenever needed. In this context, continuously available supervision by physicians with curricular training and certification in hemodynamics and echocardiography in the field of anesthesiology/ intensive care/cardiology has to be ensured.

In this article, a practical step-by-step approach towards a perioperative echocardiographic-based hemodynamic optimization for high-risk surgical patients is presented. It should be noted that the proposed algorithm may be used as a diagnostic tool "as needed", e.g. patients presenting with hemodynamic instability or signs of hypoperfusion, or "as a predefined monitoring tool" within a goal-directed treatment strategy, e.g. major abdominal/vascular surgery. In the latter case physicians have to set monitoring intervals which they think may appropriately address the patient's hemodynamic risk as echocardiography is a discontinuous method. Here, frequency of echocardiographic evaluations determines the ability to optimize hemodynamics. In addition, using the proposed algorithm as a predefined monitoring tool, it may be beneficial being able to compare recent echocardiographic findings intra-/postoperatively with a preoperative baseline exam. It should be noted that possible hemodynamic relevant echocardiographic findings must always be interpreted while integrating the clinical situation along with the patients' medical background.

\section{Main text}

In order to properly perform a focused echocardiography, the following views should be used: (1) TTE: parasternal long (PLAX) and short axis (PSAX), apical (4C) or subcostal 4-chamber view (S4C) with subcostal view of the inferior vena cava (SIVC); (2) TEE: midesophageal 4-chamber view (ME4C), midesophageal view of the superior vena cava (SVC), transgastric short axis view (TGSAX) [33]. In addition to the two-dimensional echocardiographic evaluation, the use of (color) doppler modalities may allow for limited qualitative evaluation of the heart valves [34]. Both TTE and TEE analysis are applicable, however, TEE may offer overall better image quality, particularly if lungs are mechanically ventilated or a transthoracic/subcostal approach is not feasible, e.g. lung surgery. It may also be preferable in patients who presenting with obesity. The major drawback of the TEE approach is a higher invasiveness, along with a longer "set-up" time. Non-invasive TTE may be more practical, especially in non-cardiac surgery cases and in ICU, where a rapid diagnostic is needed in the event of hemodynamic instability or as a (preoperative) screening tool ("baseline exam") [35]. To our knowledge, no study has directly compared the efficiency of TTE with TEE with regards to their respective effectiveness in determining intra-operative cardiac function amongst high-risk patients. Therefore no data exist on the preference of one technique over the other, and we leave that choice up to the clinician involved in the case. Nevertheless, image acquisition will be impossible in some patients at all as well as in most patients in prone position.

\subsection{Step 1: Evaluation of "Cardiac filling impairment"}

If cardiac filling is impaired by pericardial effusion/tamponade as shown in Fig. 1 ("obstructive shock"), evacuation (interventional or surgical) has the highest priority. Not only in the cardiac surgery setting, but also due to trauma or due to chronic disease, a relevant accumulation of fluid in the pericardium can occur. Within the "Focused Assessment with Sonography in Trauma" algorithm (FAST) the orienting visualization of all four heart chambers with the possibility of visualizing pericardial effusion is therefore an integral part of initial trauma assessment [36-39]. Echocardiographic signs of hemodynamically relevant pericardial effusions with a given clinical history and/or symptomatology may include: identification of pericardial effusion with consecutive hypovolemia of all heart chambers, collapse of the right cardiac chambers and/or dilatation of the inferior vena cava (SIVC). When using a TTE, the S4C view should be used, while for TEE, the ME4C should be used initially.

\subsection{Step 2: Evaluation of "Volume status/ responsiveness"}

Once any immediate impairment of cardiac filling has been ruled out, the second step is to estimate the volume status/ responsiveness of the patient, as both hypo- and hypervolemia can reduce $\mathrm{SV}$ and thus $\mathrm{DO}_{2}$. To assess the volume status, the 4-chamber views (4C) as well as the short axis views (SAX) at the level of the papillary muscles are suitable for obtaining a quick overview.

Although resting diameters for cardiac chambers are gender and body surface area specific [40], the size of the left ventricle (LV) and the right ventricle (RV) should be measured with regards to overall volume status. An enddiastolic left ventricular diameter (LVEDD) of 35-55 mm may reflect normal LV and a basal RV diameter $\leq 41 \mathrm{~mm}$ may reflect normal RV size. Qualitatively, substantial hypovolemia may be identified by the "kissing papillary muscle" sign of the corresponding ventricle. This sign is best witnessed during the systolic period, whereby the opposite myocardial walls of the associated ventricle come in contact with one another. Occasionally, hypovolemia will aggravate a dynamic flow obstruction in the left ventricular outflow tract (LVOT) in case of LV hypertrophy. It should be noted, that a pronounced concentric hypertrophy as evidenced by 


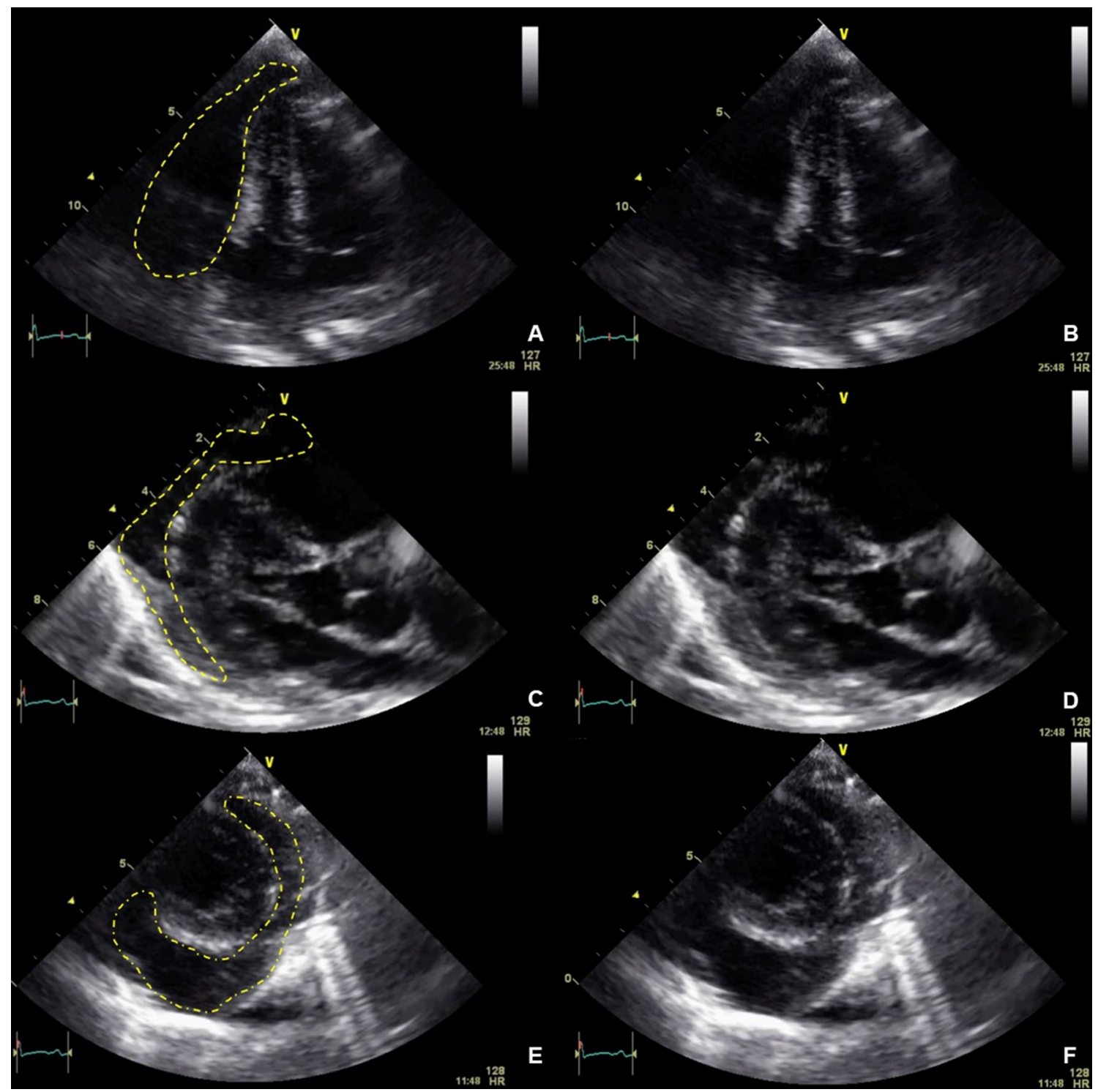

Fig. 1 Pericardial tamponade. a Highlighted in yellow, via 4C view. b Without highlights, via 4C view. c Highlighted in yellow, via PLAX view. d Without highlights, via PLAX view. e Highlighted in yellow, via PSAX view. f Without highlights, via PSAX view

a myocardial wall thickness of $>14 \mathrm{~mm}$ (i.e., due to severe aortic stenosis or as primary disease as displayed in Fig. 2) must be excluded prior to the diagnose of hypovolemia [41]. In addition, a preoperative dilated LV (e.g. LVEDD $65 \mathrm{~mm}$ ) with a reduced global systolic function may be interpreted as "hypovolemic" if the LVEDD is within normal range (e.g. LVEDD $50 \mathrm{~mm}$ ) and $\mathrm{DO}_{2}$ is reduced.

With regards to atrial volume status, a visual assessment of the interatrial septum (IAS) in the 4-chamber views (4C, ME4C) can be used for qualitative estimation of atrial filling pressures. During states of low bi-atrial filling such as during global hypovolemia, a hypermobile IAS is commonly observed. With increasing left atrial filling pressure, the IAS appears permanently convex to the right (as displayed in Fig. 3), whereas with increased right atrial filling pressure, the IAS appears permanently convex to the left atrium in combination with left cardiac hypovolemia [42]. In the context of global hypervolemia, all heart chambers appear "overfilled" or "stretched" and the IAS is usually fixated in the middle $[43,44]$.

Volume status/responsiveness can be estimated by measuring the superior vena cava (SVC) via TEE or the inferior vena cava (IVC) via TTE as shown in Fig. 4. The SIVC diameter and its respiratory variation may be used to estimate right atrial filling pressure [45]. The normal diameter for the SIVC is $<21 \mathrm{~mm}$ in awake and spontaneously breathing patients [46]. Due to the increased intrathoracic pressure exerted during mechanical inspiration, venous 


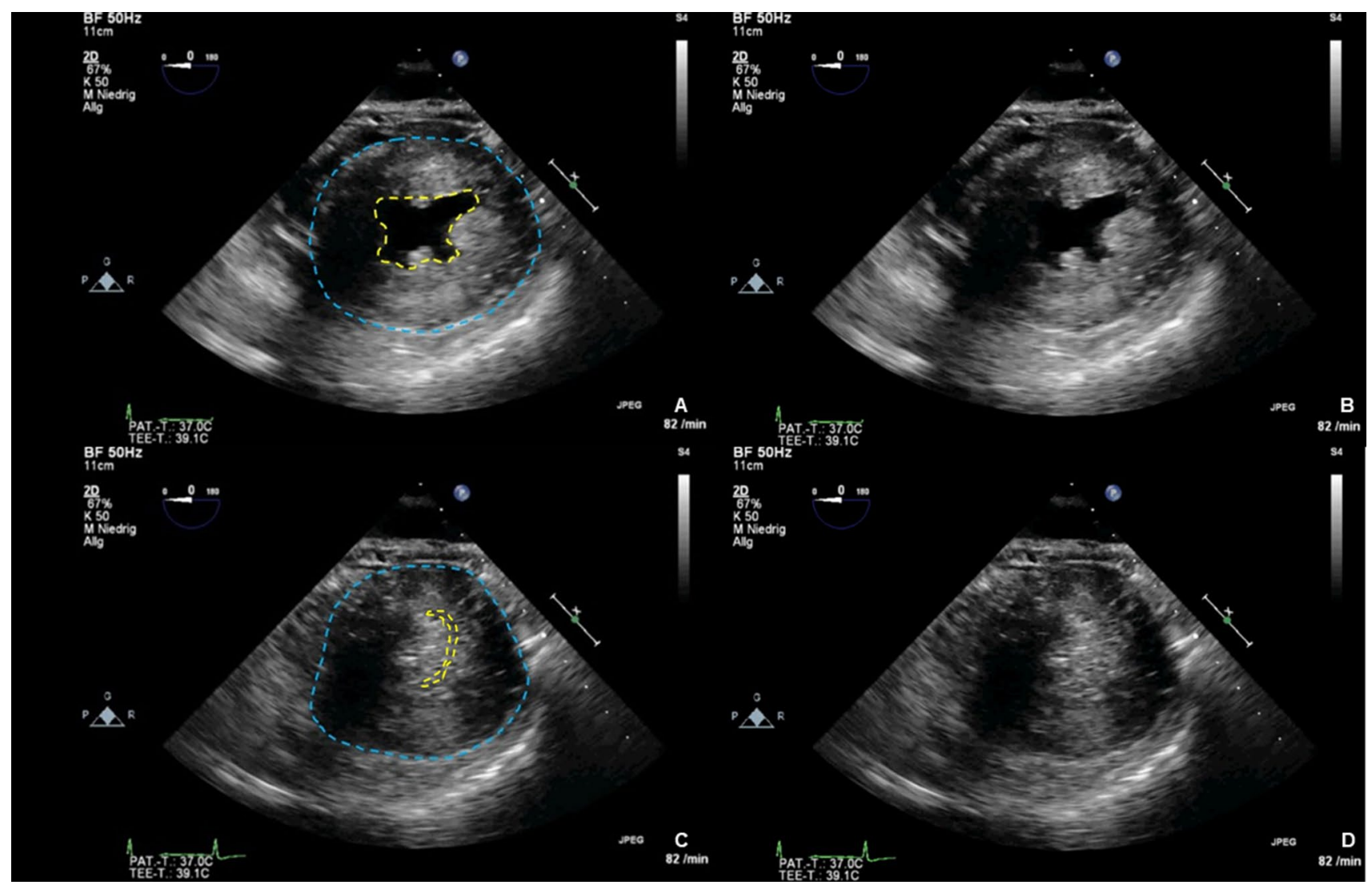

Fig. 2 Concentric hypertrophy. a End diastolic, with endocardium highlighted in yellow and epicardium highlighted in blue, via PSAX view. b End diastolic, without highlights, via PSAX view. $\mathbf{c}$ End sys- tolic, with epicardium highlighted in blue, via PSAX view. d End systolic, without highlights, via PSAX view

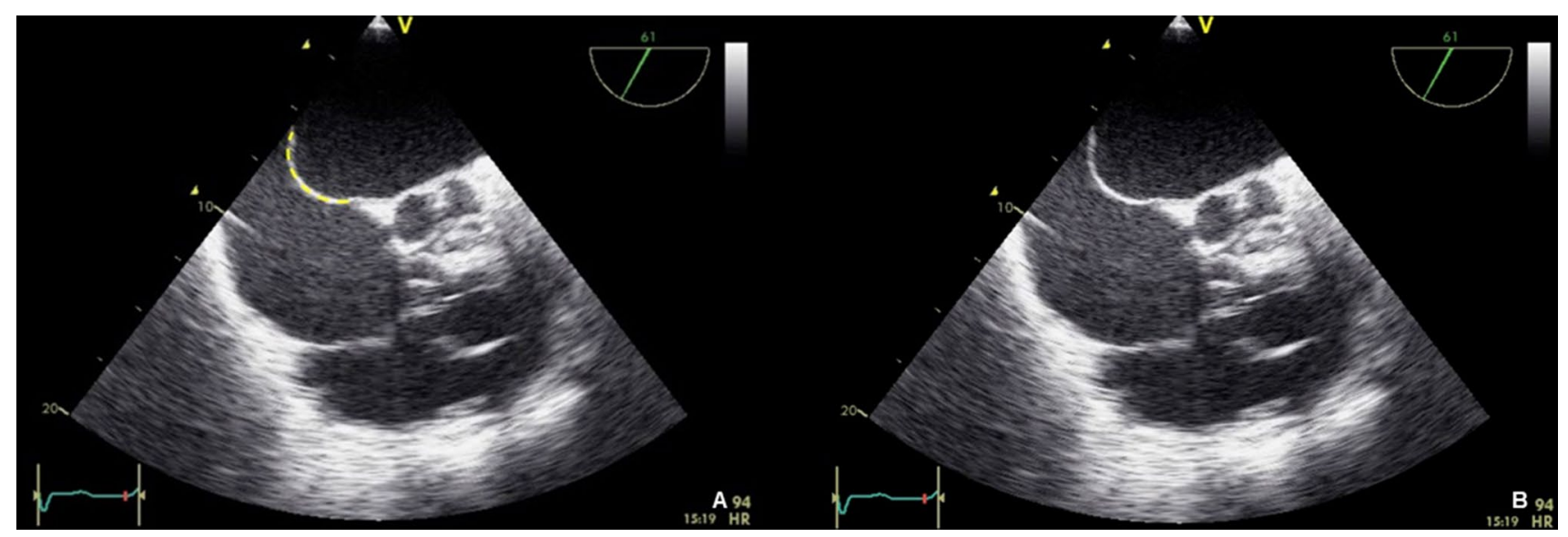

Fig. 3 Right convex interatrial septum. a Septum highlighted in yellow, via 4C view. b without highlights, via 4C view

return is reduced and the IVC distends ("SIVC-Distensibility index, DI") [47]. The more pronounced the intravascular hypovolemia, the greater the volume responsiveness, thus the greater the IVC distensibility [48]. An SIVC-DI of $>18 \%$ in controlled ventilated septic patients indicated a positive volume response with an increase in cardiac output (CO) after fluid resuscitation [49-53]. In patients with preserved spontaneous respiration, sufficient sensitivity and specificity of the SIVC-DI can also be achieved [54]: the patient is asked to inhale deeply once and exhale 


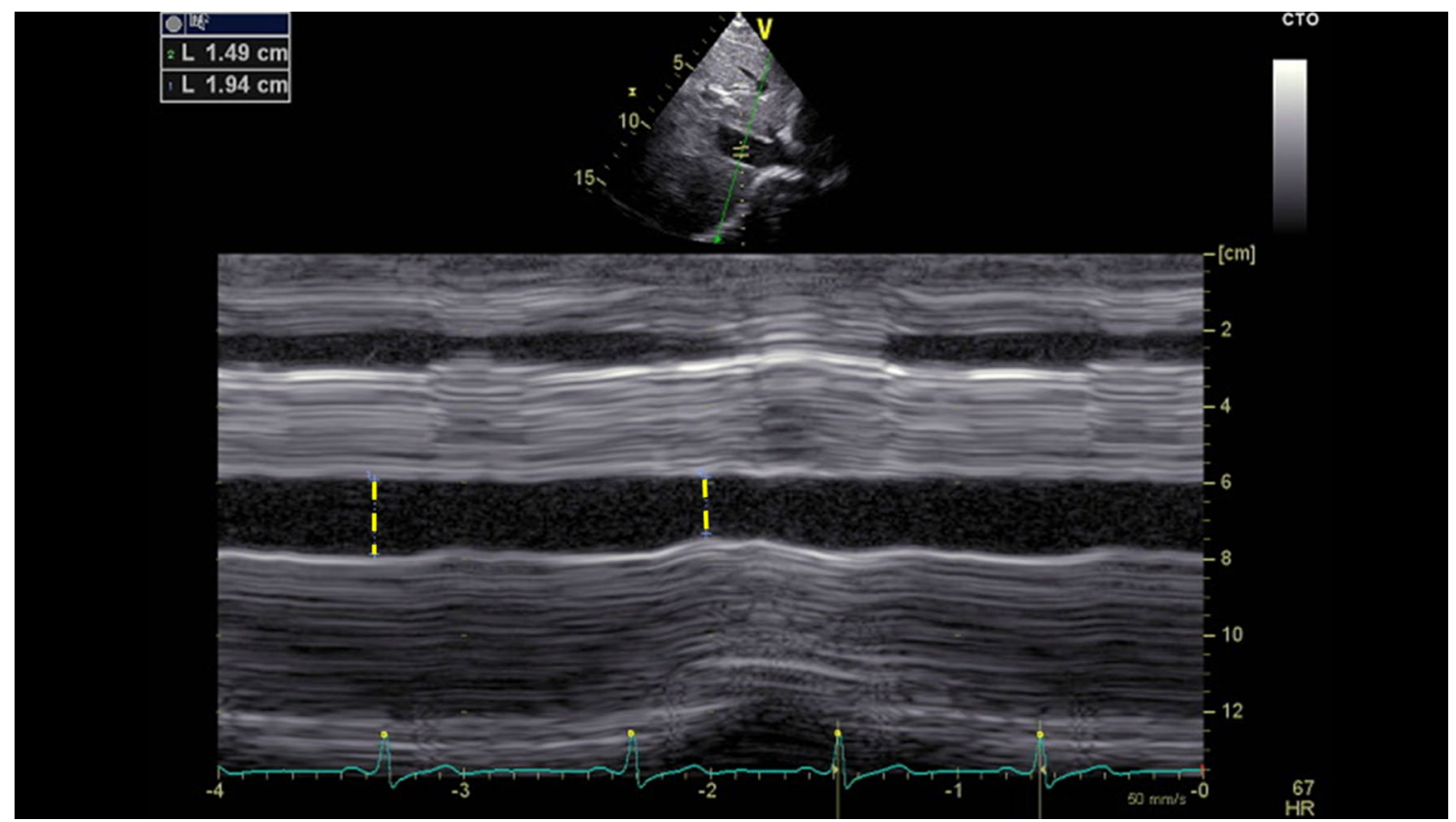

Fig. 4 Inferior vena cava via TTE. Marked in yellow is the diameter with measurements given

passively afterward, while an ultrasound measurement is continuously recorded. An SIVC diameter variability of $\geq 48 \%$ represents a positive volume responsiveness. The same is also possible with TEE using the SVC collapse index (SVC-CI) [55]. Due to the intrathoracic position, the SVC will be compressed during mechanical inspiration. Here, a SVC-CI $>36 \%$ indicates a positive volume responsiveness. However, like many other methods, these easy-to-determine quantitative variables are subject to individual cut-off variations (e.g. SIVC-DI "grey zone" $8-30 \%$ ) [53, 56-59]. Therefore, in addition to the quantitative determination of these two indices, the approach shown in Table 1 may be helpful in deciphering the measurements taken from the SIVC/SVC [60-62]. Again, physicians have to interpret echocardiographic findings in the clinical context: fluid substituon will be indicated in a trauma patient with low blood pressure, overall small heart chambers and a small vena cava inferior.

Taken together from a clinical point of view, one has to differentiate between (a) "global" hypovolemia (i.e. all heart chambers are reduced in size due to a significant reduction in total circulating blood volume-additional fluid substitution will lead to an increase in SV), (b) "relative" hypovolemia (i.e. all heart chambers appeared to be "normally" filled, however, additional fluid substitution may cause an increase in SV- "volume responsiveness") or (c) "partial" hypovolemia (i.e. LV hypovolemia in case of RV failure). In the latter, fluid substitution will mostly not be effective in increasing left ventricular SV because of the incapability of the RV to transport the blood forward into the pulmonary circulation and left heart, thus worsening RV cogestion. The determination of the exact hypovolemic cause will be

Table 1 Qualitative echocardiographic evaluation of volume status / fluid responsiveness

\begin{tabular}{|c|c|c|c|}
\hline Status & Respiratory Modulation & Interpretation & Fluid responsiveness \\
\hline $\begin{array}{l}\text { SIVC/SVC dilated (i.e. round in shape, } \\
\text { stretched, visual aspect of overfilling) }\end{array}$ & No variation & Filling pressure 仓 & $\begin{array}{l}\text { Negative } \\
\text { ("Stop signal" } \\
\text { for further fluid } \\
\text { administration) }\end{array}$ \\
\hline SIVC/SVC small/collapsed & Pronounced variation & Filling pressure $\Omega$ & Positive \\
\hline SIVC/SVC intermediate & \multicolumn{3}{|c|}{$\begin{array}{l}\text { Passive Leg Raising (PLR) and/or Fluid challenge (FC) } \\
\text { If stroke volume increases with unchanged systemic resistance, fluid substitution is clinically indi- } \\
\text { cated }\end{array}$} \\
\hline
\end{tabular}

${ }^{a}$ In the context of chronic cardiovascular disease, a positive volume responsiveness may occasionally be given despite a dilated SIVC without respiratory oscillation. Further evaluation may be done by means of PLR/FC 
detrimental in defining the amount and type of fluid resuscitation necessary.

\subsection{Step 3: RV evaluation}

A restricted RV function is associated with increased perioperative mortality [63-65]. In addition, as already mentioned, a sufficient $\mathrm{LV}$ function depends on a sufficient preload provided by the RV [66]. Therefore, the morphology and function of the RV should be assessed prior to LV assessment [67].

In addition to the points mentioned in step 2, this is achieved visually with the help of the volume/diameter relation between the right and left ventricle, the "RV/LVIndex". A normal ratio is $\sim 0.6$, an $\mathrm{RV} / \mathrm{LV}$ index $\geq 1.0$ indicates a severe RV dilatation as shown in Fig. 5 [68].

In case of RV dysfunction, hypertrophy of the free right ventricular wall $(>5 \mathrm{~mm}$ ) may indicate a chronic disease process [69]. The thickness of the right ventricular wall is best measured from subcostal at the level of the anterior tricuspid valve tip under recess of trabeculae and papillary muscles. Alternatively, measurement of the thickness of the right ventricle may be performed in the PLAX [45].

Contractility of the RV is visually assessed in the 4-chamber views. With a normal RV function, the free $\mathrm{RV}$ wall should move inwards [45]. For simple quantitative

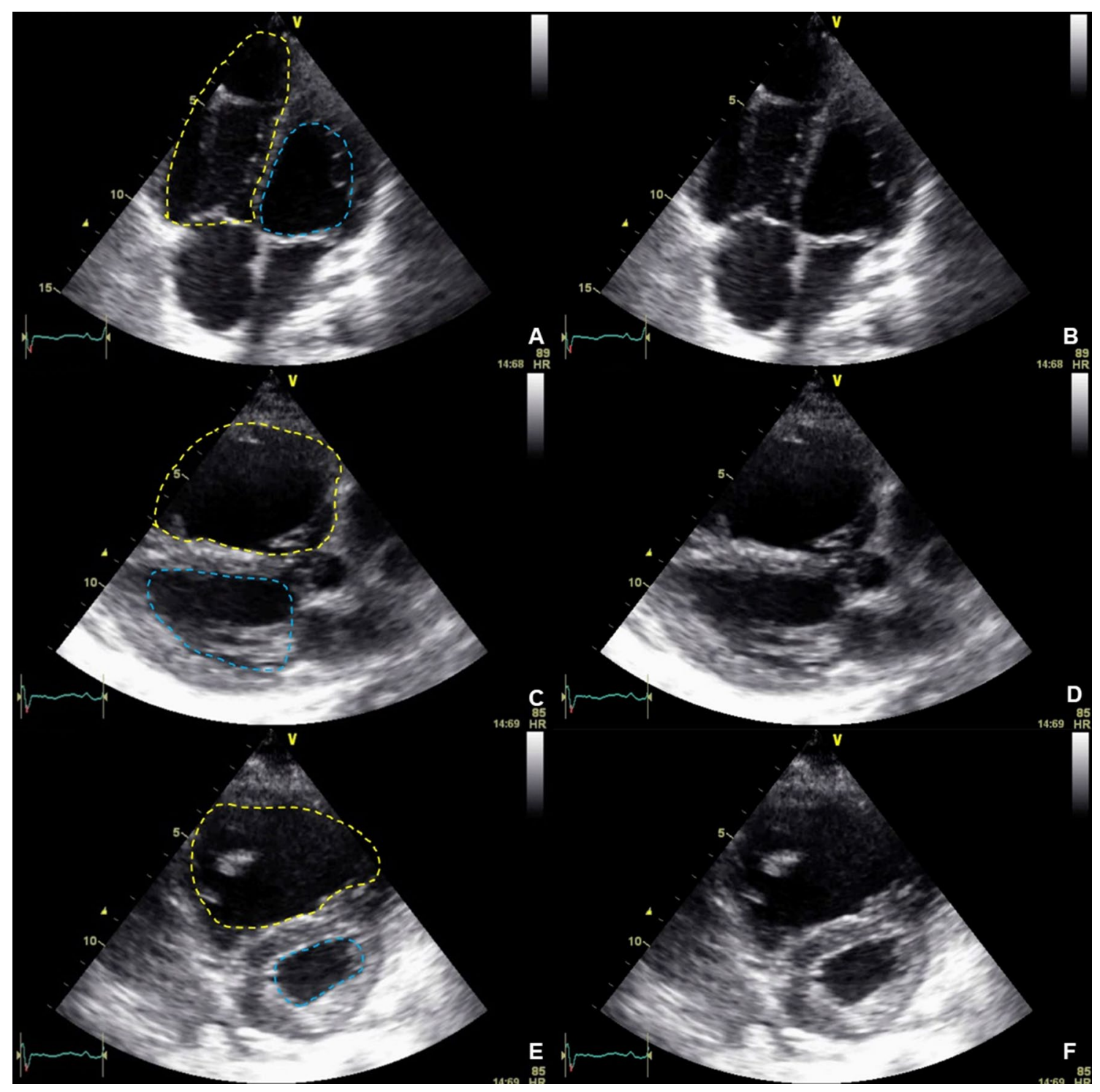

Fig. 5 Right heart dilation. a with right ventricle highlighted in yellow and left ventricle highlighted in blue, via $4 \mathrm{C}$ view. b without highlights, via $4 \mathrm{C}$ view. $\mathbf{c}$ with right ventricle highlighted in yellow and left ventricle highlighted in blue, via PLAX view. $\mathbf{d}$ without high- lights, via PLAX view. e with right ventricle highlighted in yellow and left ventricle highlighted in blue, via PSAX view. $\mathbf{f}$ without highlights, via PSAX view 
evaluation of the RV function, the amount of systolic movement of the lateral tricuspid valve annulus towards the apex (Tricuspid Annular Plane Systolic Excursion, TAPSE) can be used (Fig. 6). A TAPSE of $\geq 17 \mathrm{~mm}$ indicates normal systolic RV function [45]. If RV dilatation and systolic impairment are observed, this mostly reflects severe, and hemodynamic relevant RV dysfunction.

In addition to advanced diagnostics and consecutive therapy of the primary cause of RV dysfunction (e.g. lysis in pulmonary embolism or revascularization in RV infarction), hemodynamic optimization should aim at optimizing $\mathrm{RV}$ preload, ensuring coronary perfusion pressure, as well as inotropic support and pulmonary afterload reduction if indicated [67, 70-73]. Importantly, optimizing RV preload must be performed with great caution to avoid volume overload. RV volume overload is detrimental not only for the contractile function of the $\mathrm{RV}$, but also for coronary perfusion, venous, and intramural perfusion pressure of other organs such as the kidney. Furthermore, LV output is dependent upon the physiological geometry of the RV and the septum. Hence, RV overloading can displace the interventricular septum towards the LV ("paradoxical septum shift"), thereby restricting LV contractility. If the required therapeutic interventions are not successful, extracorporeal support-if available—may be considered [72, 74]. If the $\mathrm{RV}$ is assessed as "non-dilated, normal systolic function", hemodynamically relevant RV dysfunction is excluded and one can proceed to step 4.

\subsection{Step 4: LV evaluation}

In the fourth step, the LV should now be assessed in an analogous manner to the RV with regard to size and global systolic function (see also steps 2 and 3). The left ventricular ejection fraction (LVEF) is determined to quantify global systolic function. For normal clinical concerns, however, a qualitative assessment of the LVEF ("eye balling") may be equivalent to a quantitative [75]. The transthoracic parasternal short axis view (PSAX) or the transgastric central papillary short axis view (TGSAX) as well as 4-chamber views (4C or ME4C) allow for a quick orientation (Fig. 7) [76].

If the LV appears non-dilated with normal systolic function (LVEF > 50\%), relevant systolic LV dysfunction is excluded. However, isolated diastolic LV dysfunction (Heart failure with preserved ejection fraction, $\mathrm{HFpEF}$ ) may be present, thereby affecting overall hemodynamic functioning [77]. Evaluation of diastolic function is outside of the scope of a hemodynamic focused echocardiography. If diastolic dysfunction is suspected, an expert consultation should be made in order to guide further diagnostics and therapy [78]. Qualitatively, a pronounced dilation of the left atrium (LA) in conjunction with a "stiff" and/or hypertrophied LV with normal systolic function in a breathless patient may be related to HFpEF [79]. In symptomatic patients LV afterload should be reduced and fluid substitution should be restricted $[24,80]$.

In the case of a non-dilated LV with slightly to moderately reduced global systolic function (heart failure with mid-range ejection fraction (HFmrEF), LVEF 40-49\%),

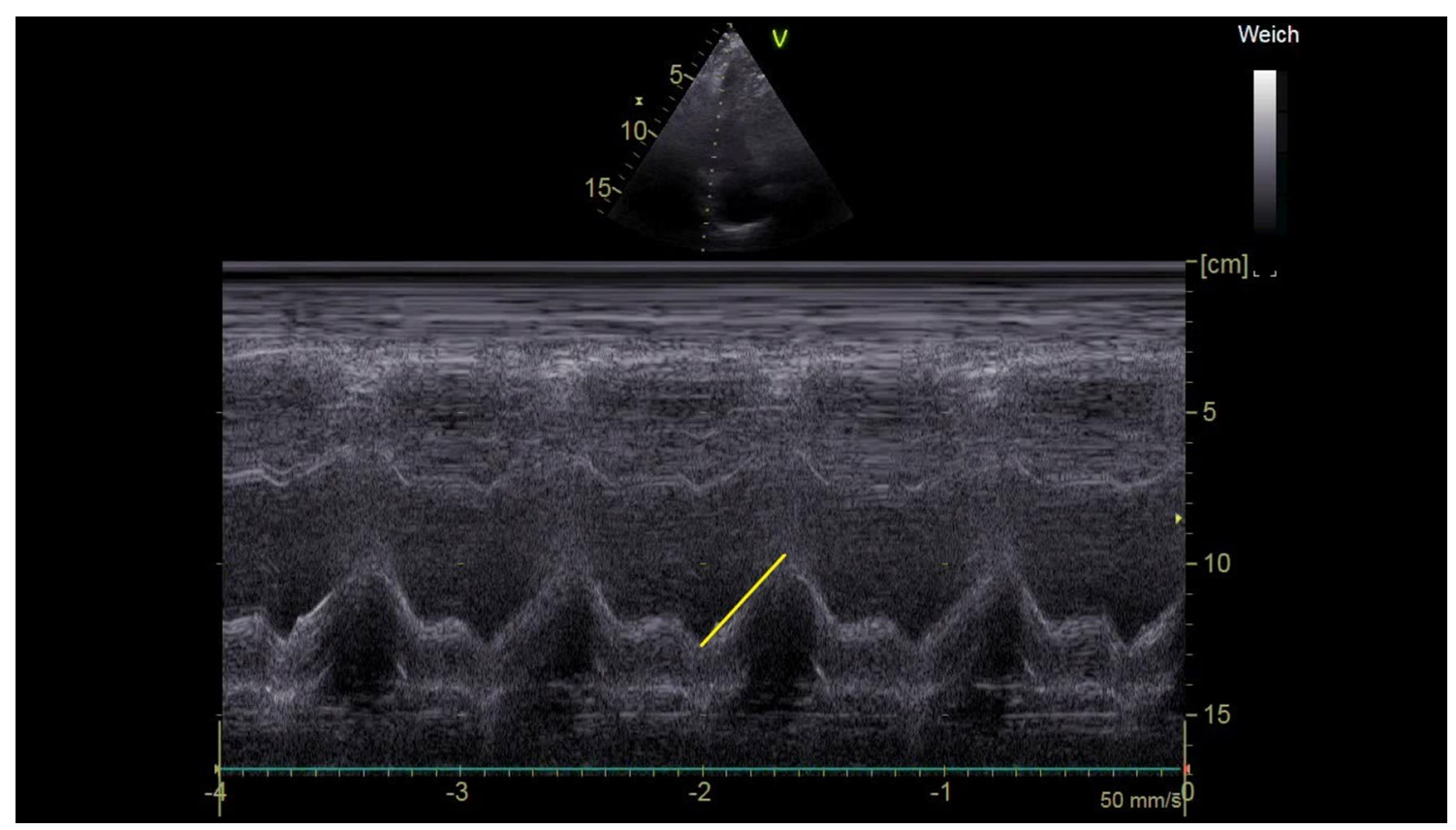

Fig. 6 TAPSE, with tricuspid annulus excursion marked in Motion-Mode 


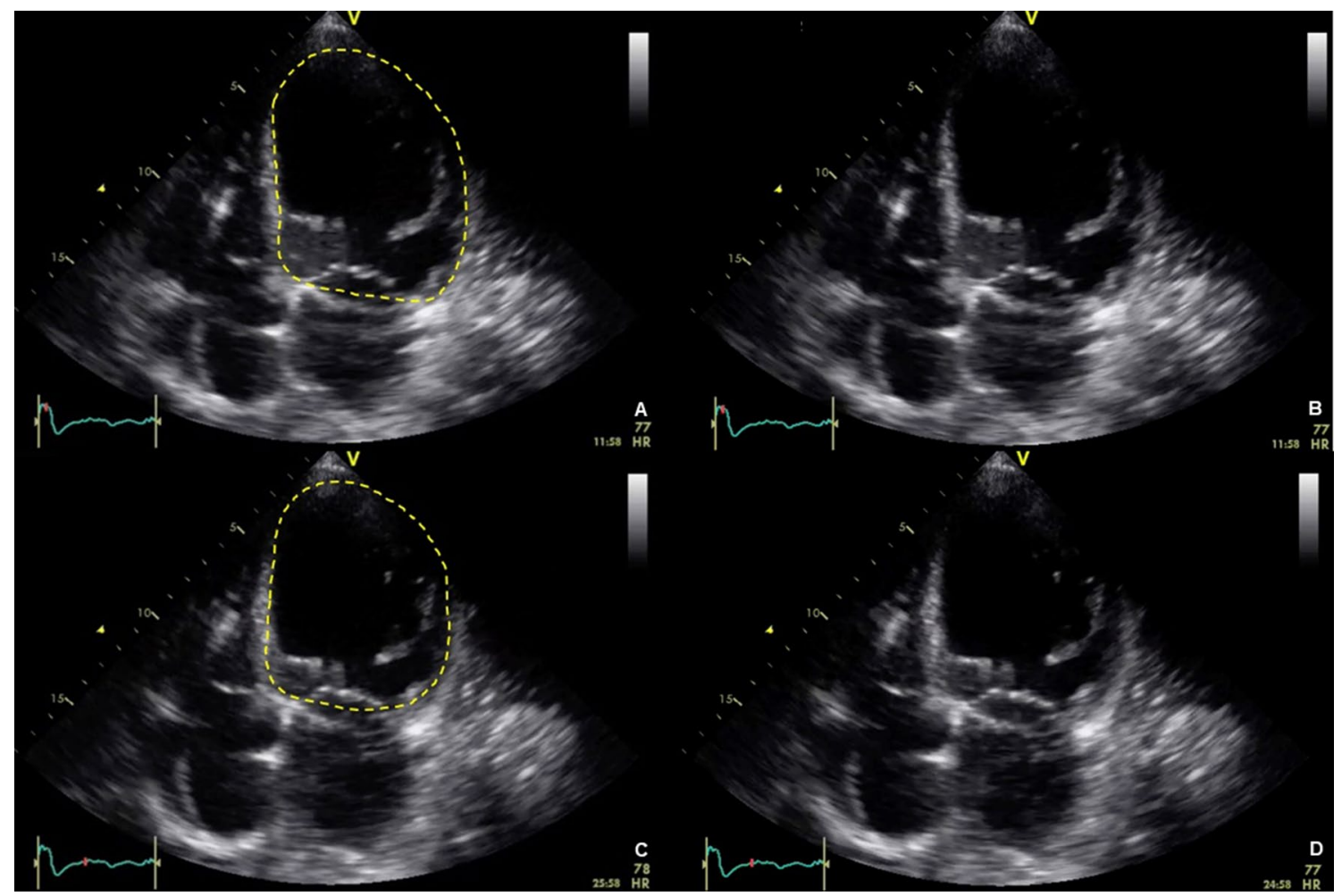

Fig. 7 Left ventricular dysfunction. a End diastolic phase, left ventricle highlighted in yellow, via $4 \mathrm{C}$ view. b End diastolic phase, without highlights, via $4 \mathrm{C}$ view. c Dilation in end systolic phase, left ventricle

cardiac preload should be optimized and inotropic support may be administered to improve $\mathrm{DO}_{2}[74,81]$. In a dilated LV with severely reduced global systolic function (heart failure with reduced ejection fraction (HFrEF) with LVEF $<40 \%$ ) an intensified inotropic therapy in conjunction with preload optimization is indicated in situations of hemodynamic instability. A vasopressor may be considered in case of cardiogenic shock with persistent hypoperfusion, despite treatment with an inotropic agent, to increase blood pressure and vital organ perfusion pressure [24]. If conservative therapy does not improve $\mathrm{DO}_{2}$, mechanical support and/ or implantation of a left ventricular microaxial pump may be discussed. Lastly, if (new) regional wall motion abnormalities are detected, specifically LV wall hypokinesia, akinesia or dyskinesia [82], this may hint at specific cause such as myocardial infarction or Takotsubo syndrome, which require specific diagnostic testing (e.g. electrocardiogram, cardiac enzymes, coronary angiography) and treatment.

\subsection{Step 5: Evaluation of „Valve morphology and function"}

Echocardiography allows for a comprehensive morphological and functional assessment of the heart valves. The visual and thus qualitative evaluation of valves in the hemodynamic highlighted in yellow, via 4C view. d Dilation in end systolic phase, without highlights, via $4 \mathrm{C}$ view

focused examination is used to assess valve opening and closure as well as to recognize morphological abnormalities. Hemodynamic relevant valve dysfunction may be excluded if thin leaflets with a normal opening/closing and without turbulent flow in color Doppler have been determined in $\geq 2$ cross-sectional views. If a thickened or calcified valve with a restricted opening is apparent, hemodynamic relevant stenosis may be suspected, especially in the case of antegrade flow accelerations/turbulences in color Doppler. In addition, hemodynamic relevant regurgitation might be suspected if an exaggerated leaflet motion or visuable coaptation defect during valve closing is observed in conjunction with a wide, turbulent colour jet ("vena contracta") depicting significant backward flow (Fig. 8) [34]. However, in case of hemodynamically relevant valve abnormalities in the focused examination, a detailed evaluation should be carried out immediately by a certified examiner [83-85].

\subsection{Step 6: Rating cardiac output}

Transthoracic and transesophageal echocardiography are capable of rating cardiac output, although discontinuously, using continuous-wave (cw) Doppler across the left ventricular outflow tract (LVOT) / aortic valve (AV) measuring the velocity time integral (VTI) (Fig. 9) [86]. Prior 
Fig. 8 Mitral valve regurgitation, with doppler, via $4 \mathrm{C}$ view
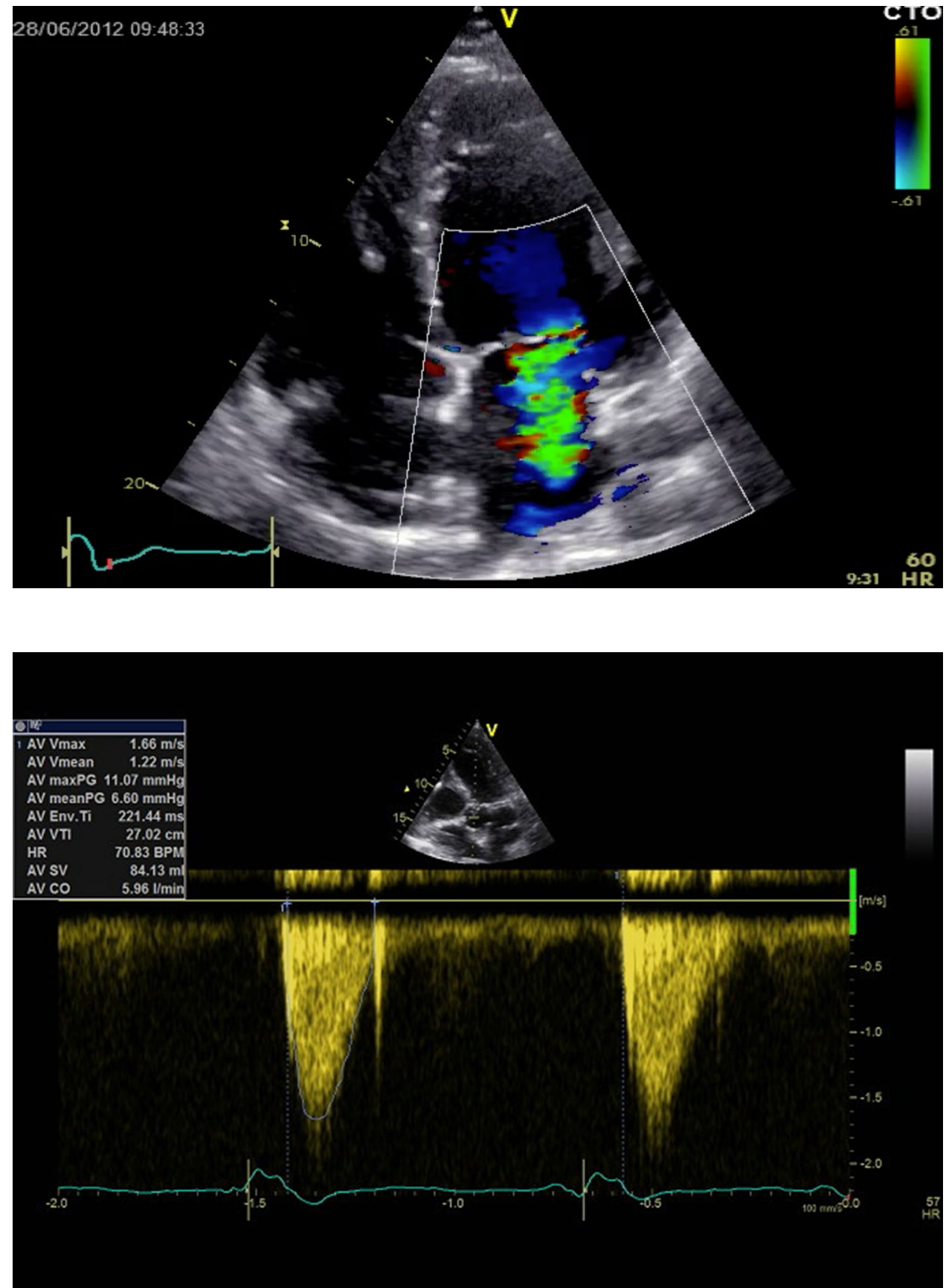

Fig. 9 Continouous wave Doppler across the aortic valve to measure the velocity time integral to this, aortic stenosis must be excluded (see Step 5). A VTI of 18-22 cm indicates normal stroke volume, whereas a VTI $<18 \mathrm{~cm}$ is suspective of decreased stroke volume and $>22 \mathrm{~cm}$ of an increased one [86]. In a prospective observational study Mercado et al. found out that in critically ill mechanically ventilated patients the transthoracic echocardiography was an accurate and precise method for estimating cardiac output [87]. In contrast, amongst patients undergoing cardiac surgery, echocardiography is not interchangeable with cardiac output monitoring by pulmonary catheter thermodilution [88]. Thus, after and/ or simultaneously to initial echocardiographic evaluation, a continuous hemodynamic monitoring should be implemented in hemodynamic unstable patients to assess therapeutic success. In patients with refractory shock associated with a right ventricular dysfunction, a pulmonary artery catheter in addition to echocardiography is recommended [89]. Most other conditions may be monitored by transpulmonary thermodilution [90]. 


\section{Conclusions}

Hemodynamic focused echocardiography as a rapid diagnostic method, offers an excellent opportunity to examine signs of filling impairment, cardiac preload, myocardial contractility and the function of the heart valves. We thus suggest a 6-step-echocardiohgraphic approach to assess high-risk cardiac patients with in the perioperative setting to rapidly pinpoint intra-cardiac pathophysiology. In conclusion, the summary of all echocardiographic findings, including clinical symptoms, allows for a differentiated assessment of patient's cardiovascular function and can thus help to guide a (patho)physiological-orientated and individualized hemodynamic therapy in order to optimize/ maintain SV.

Acknowledgments Open Access funding provided by Projekt DEAL.

Author contributions ME and RFT used the algorithm clinically, wrote the manuscript with $\mathrm{MN}$ and designed the figures. ST developed the algorithm and initiated the manuscript. HVG, GM, RP, DR, TWLS and $\mathrm{CB}$ critically reviewed the manuscript and helped to precisely describe the steps of echocardiographic assessment.

\section{Funding None.}

Data availability Not applicable

\section{Compliance with ethical standards}

Conflict of interest ME and MN have nothing to declare. HVG received personal fees from GE Healthcare, outside the submitted work. GM received lecture fees from Pfizer, Novartis, Servier, ZOLL and Orion Pharma. RP has nothing to declare. DR received honoraria for advisory services and lecturing from Pulsion Medical Systems SE, Masimo Inc., Fresenius-Kabi and Ratiopharm. TWLS received honoraria from Edwards Lifesciences (Irvine, CA, USA) and Masimo Inc. (Irvine, CA, USA) for consulting and lecturing and from Pulsion Medical Systems SE (Feldkirchen, Germany) for lecturing. CB and RFT have nothing to declare. ST received honoraria for lectures from Edwards, Carinopharm, OrionPharma and Smith \& Nephews outside this work.

Ethics approval Not applicable.

Informed consent Not applicable.

Open Access This article is licensed under a Creative Commons Attribution 4.0 International License, which permits use, sharing, adaptation, distribution and reproduction in any medium or format, as long as you give appropriate credit to the original author(s) and the source, provide a link to the Creative Commons licence, and indicate if changes were made. The images or other third party material in this article are included in the article's Creative Commons licence, unless indicated otherwise in a credit line to the material. If material is not included in the article's Creative Commons licence and your intended use is not permitted by statutory regulation or exceeds the permitted use, you will need to obtain permission directly from the copyright holder. To view a copy of this licence, visit http://creativecommons.org/licenses/by/4.0/.

\section{References}

1. Lieberman JA, Weiskopf RB, Kelley SD, Feiner J, Noorani M, Leung J, Toy P, Viele M. Critical oxygen delivery in conscious humans is less than $7.3 \mathrm{ml} \mathrm{O} 2 \times \mathrm{kg}(-1) \times \mathrm{min}(-1)$. Anesthesiology. 2000;92(2):407-13.

2. Shoemaker WC, Appel PL, Kram HB. Hemodynamic and oxygen transport responses in survivors and nonsurvivors of high-risk surgery. Crit Care Med. 1993;21(7):977-90.

3. Hammill BG, Curtis LH, Bennett-Guerrero E, O’Connor CM, Jollis JG, Schulman KA, Hernandez AF. Impact of heart failure on patients undergoing major noncardiac surgery. Anesthesiology. 2008;108(4):559-67.

4. Hamilton MA, Cecconi M, Rhodes A. A systematic review and meta-analysis on the use of preemptive hemodynamic intervention to improve postoperative outcomes in moderate and high-risk surgical patients. Anesth Analg. 2011;112(6):1392-402. https:// doi.org/10.1213/ANE.0b013e3181 eeaae5.

5. Aya HD, Cecconi M, Hamilton M, Rhodes A. Goal-directed therapy in cardiac surgery: a systematic review and meta-analysis. $\mathrm{Br}$ J Anaesth. 2013;110(4):510-7. https://doi.org/10.1093/bja/aet02 0 .

6. Pearse R, Dawson D, Fawcett J, Rhodes A, Grounds RM, Bennett ED. Early goal-directed therapy after major surgery reduces complications and duration of hospital stay. A randomised, controlled trial [ISRCTN38797445]. Crit Care. 2005;9(6):687-93. https:// doi.org/10.1186/cc3887.

7. Grocott MP, Mythen MG, Gan TJ. Perioperative fluid management and clinical outcomes in adults. Anesth Analg. 2005;100(4):1093106. https://doi.org/10.1213/01.ANE.0000148691.33690.AC.

8. Chong MA, Wang Y, Berbenetz NM, McConachie I. Does goaldirected haemodynamic and fluid therapy improve peri-operative outcomes?: a systematic review and meta-analysis. Eur J Anaesthesiol. 2018;35(7):469-83. https://doi.org/10.1097/eja.00000 00000000778 .

9. Ebm C, Cecconi M, Sutton L, Rhodes A. A cost-effectiveness analysis of postoperative goal-directed therapy for high-risk surgical patients. Crit Care Med. 2014;42(5):1194-203. https://doi. org/10.1097/ccm.0000000000000164.

10. Tanczos K, Nemeth M, Molnar Z. The multimodal concept of hemodynamic stabilization. Front Public Health. 2014;2:34. https ://doi.org/10.3389/fpubh.2014.00034.

11. Vincent J-L, Rhodes A, Perel A, Martin GS, Della Rocca G, Vallet B, Pinsky MR, Hofer CK, Teboul J-L, de Boode W-P, Scolletta S, Vieillard-Baron A, De Backer D, Walley KR, Maggiorini M, Singer M. Clinical review: update on hemodynamic monitoringa consensus of 16. Crit Care. 2011. https://doi.org/10.1186/cc102 91.

12. Bundgaard-Nielsen M, Holte K, Secher NH, Kehlet H. Monitoring of peri-operative fluid administration by individualized goaldirected therapy. Acta Anaesthesiol Scand. 2007;51(3):331-40.

13. Le Manach Y, Hofer CK, Lehot JJ, Vallet B, Goarin JP, Tavernier B, Cannesson M. Can changes in arterial pressure be used to detect changes in cardiac output during volume expansion in the perioperative period? Anesthesiology. 2012;117(6):1165-74.

14. Cholley BP, Vieillard-Baron A, Mebazaa A. Echocardiography in the ICU: time for widespread use! Intensive Care Med. 2006;32(1):9-10. https://doi.org/10.1007/s00134-005-2833-8.

15. Balzer F, Trauzeddel RF, Ertmer M, Erb J, Heringlake M, Groesdonk HV, Goepfert M, Reuter DA, Sander M, Treskatsch S. Utilisation of echocardiography in intensive care units: results of an online survey in Germany. Minerva Anestesiol. 2018. https://doi. org/10.23736/S0375-9393.18.12657-5.

16. Price S, Platz E, Cullen L, Tavazzi G, Christ M, Cowie MR, Maisel AS, Masip J, Miro O, McMurray JJ, Peacock WF, 
Martin-Sanchez FJ, Di Somma S, Bueno H, Zeymer U, Mueller C. Expert consensus document: echocardiography and lung ultrasonography for the assessment and management of acute heart failure. Nat Rev Cardiol. 2017;14(7):427-40. https://doi. org/10.1038/nrcardio.2017.56.

17. Bainbridge D, McConnell B, Royse C. A review of diagnostic accuracy and clinical impact from the focused use of perioperative ultrasound. Can J Anesth. 2018;65(4):371-80. https://doi. org/10.1007/s12630-018-1067-5.

18. Feng M, McSparron JI, Kien DT, Stone DJ, Roberts DH, Schwartzstein RM, Vieillard-Baron A, Celi LA. Transthoracic echocardiography and mortality in sepsis: analysis of the MIMICIII database. Intensive Care Med. 2018;44(6):884-92. https://doi. org/10.1007/s00134-018-5208-7.

19. Cioccari L, Zante B, Bloch A, Berger D, Limacher A, Jakob SM, Takala J, Merz TM. Effects of hemodynamic monitoring using a single-use transesophageal echocardiography probe in critically ill patients - study protocol for a randomized controlled trial. Trials. 2018;19(1):362. https://doi.org/10.1186/s13063-018-2714-4.

20. Bouferrache K, Amiel JB, Chimot L, Caille V, Charron C, Vignon $\mathrm{P}$, Vieillard-Baron A. Initial resuscitation guided by the Surviving Sepsis Campaign recommendations and early echocardiographic assessment of hemodynamics in intensive care unit septic patients: a pilot study. Crit Care Med. 2012;40(10):2821-7. https://doi. org/10.1097/CCM.0b013e31825bc565.

21. Cheitlin MD, Armstrong WF, Aurigemma GP, Beller GA, Bierman FZ, Davis JL, Douglas PS, Faxon DP, Gillam LD, Kimball TR, Kussmaul WG, Pearlman AS, Philbrick JT, Rakowski H, Thys DM, Antman EM, Smith SC Jr, Alpert JS, Gregoratos G, Anderson JL, Hiratzka LF, Faxon DP, Hunt SA, Fuster V, Jacobs AK, Gibbons RJ, Russell RO. ACC/AHA/ASE 2003 Guideline Update for the Clinical Application of Echocardiography: summary article. A report of the American College of Cardiology/ American Heart Association Task Force on Practice Guidelines (ACC/AHA/ASE Committee to Update the 1997 Guid. J Am Soc Echocardiogr. 2003;16(10):1091-110. https://doi.org/10.1016/ S0894-7317(03)00685-0.

22. Manning WJPD. Clinical cardiovascular magnetic resonance imaging techniques. In: Cardiovascular Magnetic Resonance, vol 2. Elsevier, Philadelphia; 2010, p.19-36

23. Cecconi M, De Backer D, Antonelli M, Beale R, Bakker J, Hofer C, Jaeschke R, Mebazaa A, Pinsky MR, Teboul JL, Vincent JL, Rhodes A. Consensus on circulatory shock and hemodynamic monitoring. Task force of the European Society of Intensive Care Medicine. Intensive Care Med. 2014;40(12):1795-815. https:// doi.org/10.1007/s00134-014-3525-z.

24. Ponikowski P, Voors AA, Anker SD, Bueno H, Cleland JG, Coats AJ, Falk V, Gonzáles-Juanatey JR, Harjola VP, Jankowska EA, Jessup M, Linde C, Nihoyannopoulos P, Parissis JT, Pieske B, Riley JP, Rosano GM, Ruilope LM, Ruschitzka F, Rutten FH, van der Meer P, Members ATF. 2016 ESC Guidelines for the diagnosis and treatment of acute and chronic heart failure: the task force for the diagnosis and treatment of acute and chronic heart failure of the European Society of Cardiology (ESC) Developed with the special contribution of the Heart Failure Association (HFA) of the ESC. Eur Heart J. 2016;37(27):2129-200. https://doi.org/10.1093/ eurheartj/ehw128.

25. Kanji HD, McCallum J, Sirounis D, MacRedmond R, Moss R, Boyd JH. Limited echocardiography-guided therapy in subacute shock is associated with change in management and improved outcomes. J Crit Care. 2014;29(5):700-5. https://doi.org/10.1016/j. jcrc.2014.04.008.

26. Jensen MB, Sloth E, Larsen KM, Schmidt MB. Transthoracic echocardiography for cardiopulmonary monitoring in intensive care. Eur J Anaesthesiol. 2004;21(9):700-7.
27. Benjamin E, Griffin K, Leibowitz AB, Manasia A, Oropello JM, Geffroy V, DelGiudice R, Hufanda J, Rosen S, Goldman M. Goal-directed transesophageal echocardiography performed by intensivists to assess left ventricular function: comparison with pulmonary artery catheterization. J Cardiothorac Vasc Anesth. 1998;12(1):10-5.

28. Manasia AR, Nagaraj HM, Kodali RB, Croft LB, Oropello JM, Kohli-Seth R, Leibowitz AB, DelGiudice R, Hufanda JF, Benjamin E, Goldman ME. Feasibility and potential clinical utility of goal-directed transthoracic echocardiography performed by noncardiologist intensivists using a small hand-carried device (SonoHeart) in critically ill patients. J Cardiothorac Vasc Anesth. 2005;19(2):155-9. https://doi.org/10.1053/j.jvca.2005.01.023.

29. Reeves ST, Finley AC, Skubas NJ, Swaminathan M, Whitley WS, Glas KE, Hahn RT, Shanewise JS, Adams MS, Shernan SK, Council on Perioperative Echocardiography of the American Society of E, Society of Cardiovascular A. Basic perioperative transesophageal echocardiography examination: a consensus statement of the American Society of Echocardiography and the Society of Cardiovascular Anesthesiologists. J Am Soc Echocardiogr. 2013;26(5):443-56. https://doi.org/10.1016/j.echo.2013.02.015.

30. Greim CA, Weber S, Göpfert M, Groesdonk H, Treskatsch S, Wolf B, Zahn P, Müller M, Zenz S, Rauch H, Molitoris U, Ender J. Perioperative fokussierte Echokardiographie in der Anästhesiologie und Intensivmedizin. Anästh Intensivmed. 2017;58:616-48.

31. Spencer KT, Kimura BJ, Korcarz CE, Pellikka PA, Rahko PS, Siegel RJ. Focused cardiac ultrasound: recommendations from the American Society of Echocardiography. J Am Soc Echocardiogr. 2013;26(6):567-81. https://doi.org/10.1016/j.echo.2013.04.001.

32. Diaz-Gomez JL, Perez-Protto S, Hargrave J, Builes A, Capdeville M, Festic E, Shahul S. Impact of a focused transthoracic echocardiography training course for rescue applications among anesthesiology and critical care medicine practitioners: a prospective study. J Cardiothorac Vasc Anesth. 2015;29(3):576-81. https:// doi.org/10.1053/j.jvca.2014.10.013.

33. Treskatsch S, Balzer F, Knebel F, Habicher M, Braun JP, Kastrup M, Grubitzsch H, Wernecke KD, Spies C, Sander M. Feasibility and influence of hTEE monitoring on postoperative management in cardiac surgery patients. Int $\mathbf{J}$ Cardiovasc Imaging. 2015;31(7):1327-35. https://doi.org/10.1007/s 1055 4-015-0689-8).

34. Zoghbi WA, Adams D, Bonow RO, Enriquez-Sarano M, Foster E, Grayburn PA, Hahn RT, Han Y, Hung J, Lang RM, Little SH, Shah DJ, Shernan S, Thavendiranathan P, Thomas JD, Weissman NJ. Recommendations for noninvasive evaluation of native valvular regurgitation: a report from the American Society of Echocardiography Developed in Collaboration with the Society for Cardiovascular Magnetic Resonance. J Am Soc Echocardiogr. 2017;30(4):303-71. https://doi.org/10.1016/j.echo.2017.01.007.

35. Jorgensen MR, Juhl-Olsen P, Frederiksen CA, Sloth E. Transthoracic echocardiography in the perioperative setting. Curr Opin Anaesthesiol. 2016;29(1):46-544. https://doi.org/10.1097/ ACO.0000000000000271.

36. Kirkpatrick AW, Sirois M, Laupland KB, Liu D, Rowan K, Ball CG, Hameed SM, Brown R, Simons R, Dulchavsky SA, Hamiilton DR, Nicolaou S. Hand-held thoracic sonography for detecting post-traumatic pneumothoraces: the Extended Focused Assessment with Sonography for Trauma (EFAST). J Trauma. 2004;57(2):288-95. https://doi.org/10.1097/01.TA.0000133565 88871.E4.

37. Helling TS, Duke P, Beggs CW, Crouse LJ. A prospective evaluation of 68 patients suffering blunt chest trauma for evidence of cardiac injury. J Trauma. 1989;29(7):961-5.

38. Helling TS, Wilson J, Augustosky K. The utility of focused abdominal ultrasound in blunt abdominal trauma: a reappraisal. 
Am J Surg. 2007;194(6):728-32. https://doi.org/10.1016/j.amjsu rg.2007.08.012.

39. Medicine AIoUi, Physicians ACoE. AIUM practice guideline for the performance of the focused assessment with sonography for trauma (FAST) examination. J Ultrasound Med. 2014;33(11):2047-56.

40. Kou S, Caballero L, Dulgheru R, Voilliot D, De Sousa C, Kacharava G, Athanassopoulos GD, Barone D, Baroni M, Cardim N, Gomez De Diego JJ, Hagendorff A, Henri C, Hristova K, Lopez T, Magne J, De La Morena G, Popescu BA, Penicka M, Ozyigit T, Rodrigo Carbonero JD, Salustri A, Van De Veire N, Von Bardeleben RS, Vinereanu D, Voigt JU, Zamorano JL, Donal E, Lang RM, Badano LP, Lancellotti P. Echocardiographic reference ranges for normal cardiac chamber size: results from the NORRE study. Eur Heart J Cardiovasc Imaging. 2014;15(6):680-90. https ://doi.org/10.1093/ehjci/jet284.

41. Gaasch WH, Zile MR. Left ventricular structural remodeling in health and disease: with special emphasis on volume, mass, and geometry. J Am Coll Cardiol. 2011;58(17):1733-40. https://doi. org/10.1016/j.jacc.2011.07.022.

42. Kusumoto FM, Muhiudeen IA, Kuecherer HF, Cahalan MK, Schiller NB. Response of the interatrial septum to transatrial pressure gradients and its potential for predicting pulmonary capillary wedge pressure: an intraoperative study using transesophageal echocardiography in patients during mechanical ventilation. J Am Coll Cardiol. 1993;21(3):721-8.

43. Royse CF, Royse AG, Soeding PF, Blake DW. Shape and movement of the interatrial septum predicts change in pulmonary capillary wedge pressure. Ann Thorac Cardiovasc Surg. 2001;7(2):79-83.

44. Johansson MC, Guron CW. Leftward bulging of atrial septum is provoked by nitroglycerin and by sustained valsalva strain. J Am Soc Echocardiogr. 2014;27(10):1120-7.

45. Rudski LG, Lai WW, Afilalo J, Hua L, Handschumacher MD, Chandrasekaran K, Solomon SD, Louie EK, Schiller NB. Guidelines for the echocardiographic assessment of the right heart in adults: a report from the American Society of Echocardiography endorsed by the European Association of Echocardiography, a registered branch of the European Society of Cardiology, and the Canadian Society of Echocardiography. J Am Soc Echocardiogr. 2010;23(7):685-713. https://doi.org/10.1016/j.echo.2010.05.010.

46. Ciozda W, Kedan I, Kehl DW, Zimmer R, Khandwalla R, Kimchi A. The efficacy of sonographic measurement of inferior vena cava diameter as an estimate of central venous pressure. Cardiovasc Ultrasound. 2016;14(1):33. https://doi.org/10.1186/s1294 7-016-0076-1.

47. Barbier C, Loubières Y, Schmit C, Hayon J, Ricôme J-L, Jardin F, Vieillard-Baron A. Respiratory changes in inferior vena cava diameter are helpful in predicting fluid responsiveness in ventilated septic patients. Intensive Care Med. 2004;30(9):1740-6. https://doi.org/10.1007/s00134-004-2259-8.

48. Das SK, Choupoo NS, Pradhan D, Saikia P, Monnet X. Diagnostic accuracy of inferior vena caval respiratory variation in detecting fluid unresponsiveness: a systematic review and meta-analysis. Eur J Anaesthesiol. 2018;35(11):831-9. https://doi.org/10.1097/ EJA.0000000000000841.

49. Long E, Oakley E, Duke T, Babl FE, (PREDICT) PRiEDIC. Does respiratory variation in inferior vena cava diameter predict fluid responsiveness: a systematic review and meta-analysis. Shock. 2017;47(5):550-9. https://doi.org/10.1097/SHK.0000000000 000801.

50. Cameli M, Bigio E, Lisi M, Righini FM, Galderisi M, Franchi F, Scolletta S, Mondillo S. Relationship between pulse pressure variation and echocardiographic indices of left ventricular filling pressure in critically ill patients. Clin Physiol Funct Imaging. 2015;35(5):344-50. https://doi.org/10.1111/cpf.12168.
51. Cinotti R, Roquilly A, Mahé PJ, Feuillet F, Yehia A, Belliard G, Lejus C, Blanloeil Y, Teboul JL, Asehnoune K, ATLANRÉA Group. Pulse pressure variations to guide fluid therapy in donors: a multicentric echocardiographic observational study. J Crit Care. 2014;29(4):489-94. https://doi.org/10.1016/j.jcrc.2014.03.027.

52. Mahjoub Y, Pila C, Friggeri A, Zogheib E, Lobjoie E, Tinturier F, Galy C, Slama M, Dupont H. Assessing fluid responsiveness in critically ill patients: false-positive pulse pressure variation is detected by Doppler echocardiographic evaluation of the right ventricle. Crit Care Med. 2009;37(9):2570-5. https://doi. org/10.1097/CCM.0b013e3181a380a3.

53. Huang H, Shen Q, Liu Y, Xu H, Fang Y. Value of variation index of inferior vena cava diameter in predicting fluid responsiveness in patients with cirulatory shock receiving mechanical ventilation: a systematic review and meta-analysis. Crit Care. 2018;22(1):204. https://doi.org/10.1186/s13054-018-2063-4.

54. Preau S, Bortolotti P, Colling D, Dewavrin F, Colas V, Voisin B, Onimus T, Drumez E, Durocher A, Redheuil A, Saulnier F. Diagnostic accuracy of the inferior vena cava collapsibility to predict fluid responsiveness in spontaneously breathing patients with sepsis and acute circulatory failure. Crit Care Med. 2017;45(3):e290e297297. https://doi.org/10.1097/CCM.0000000000002090.

55. Vieillard-Baron A, Chergui K, Rabiller A, Peyrouset O, Page B, Beauchet A, Jardin F. Superior vena caval collapsibility as a gauge of volume status in ventilated septic patients. Intensive Care Med. 2004;30(9):1734-9. https://doi.org/10.1007/s00134-004-2361-y.

56. de Oliveira OH, Freitas FG, Ladeira RT, Fischer CH, Bafi AT, Azevedo LC, Machado FR. Comparison between respiratory changes in the inferior vena cava diameter and pulse pressure variation to predict fluid responsiveness in postoperative patients. J Crit Care. 2016;34:46-9. https://doi.org/10.1016/j. jcrc.2016.03.017.

57. Sobczyk D, Nycz K, Andruszkiewicz P, Wierzbicki K, Stapor M. Ultrasonographic caval indices do not significantly contribute to predicting fluid responsiveness immediately after coronary artery bypass grafting when compared to passive leg raising. Cardiovascular ultrasound. 2016;14(1):23. https://doi.org/10.1186/s1294 7-016-0065-4.

58. Sobczyk D, Nycz K, Andruszkiewicz P. Bedside ultrasonographic measurement of the inferior vena cava fails to predict fluid responsiveness in the first 6 hours after cardiac surgery: a prospective case series observational study. J Cardiothorac Vasc Anesth. 2015;29(3):663-9. https://doi.org/10.1053/j.jvca.2014.08.015.

59. Duwat A, Zogheib E, Guinot P, Levy F, Trojette F, Diouf M, Slama M, Dupont H. The gray zone of the qualitative assessment of respiratory changes in inferior vena cava diameter in ICU patients. Crit Care. 2014;18(1):R14. https://doi.org/10.1186/cc136 93.

60. (DGAI) DgfAuIeV. S3-Leitlinie Intravasale Volumentherapie beim Erwachsenen. 2014. Accessed 09 July 2018

61. Vieillard-Baron A, Evrard B, Repessé X, Maizel J, Jacob C, Goudelin M, Charron C, Prat G, Slama M, Geri G, Vignon P. Limited value of end-expiratory inferior vena cava diameter to predict fluid responsiveness impact of intra-abdominal pressure. Intensive Care Med. 2018;44(2):197-203. https://doi.org/10.1007/ s00134-018-5067-2.

62. Millington SJ. Ultrasound assessment of the inferior vena cava for fluid responsiveness: easy, fun, but unlikely to be helpful. Can J Anaesth. 2019;66(6):633-8. https://doi.org/10.1007/s12630-01901357-0.

63. Haddad F, Couture P, Tousignant C, Denault AY. The right ventricle in cardiac surgery, a perioperative perspective: II. Pathophysiology, clinical importance, and management. Anesth Analg. 2009;108(2):422-33. https://doi.org/10.1213/ane.0b013e3181 $8 \mathrm{~d} 8 \mathrm{~b} 92$. 
64. Hoeper MM, Granton J. Intensive care unit management of patients with severe pulmonary hypertension and right heart failure. Am J Respir Crit Care Med. 2011;184(10):1114-24. https:// doi.org/10.1164/rccm.201104-0662CI.

65. Bootsma IT, de Lange F, Koopsmans M, Haenen J, Boonstra PW, Symersky T, Boerma EC. Right ventricular function after cardiac surgery is a strong independent predictor for long-term mortality. J Cardiothorac Vasc Anesth. 2017;31(5):1656-62. https://doi. org/10.1053/j.jvca.2017.02.008.

66. Vlahakes GJ, Turley K, Hoffman JI. The pathophysiology of failure in acute right ventricular hypertension: hemodynamic and biochemical correlations. Circulation. 1981;63(1):87-95.

67. Carl M, Alms A, Braun J, Dongas A, Erb J, Goetz A, Goepfert M, Gogarten W, Grosse J, Heller AR, Heringlake M, Kastrup M, Kroener A, Loer SA, Marggraf G, Markewitz A, Reuter D, Schmitt DV, Schirmer U, Wiesenack C, Zwissler B, Spies C. S3 guidelines for intensive care in cardiac surgery patients: hemodynamic monitoring and cardiocirculary system. Ger Med Sci. 2010. https://doi.org/10.3205/000101.

68. Kukucka M, Stepanenko A, Potapov E, Krabatsch T, Redlin M, Mladenow A, Kuppe H, Hetzer R, Habazettl H. Right-to-left ventricular end-diastolic diameter ratio and prediction of right ventricular failure with continuous-flow left ventricular assist devices. J Heart Lung Transpl. 2011;30(1):64-9. https://doi.org/10.1016/j. healun.2010.09.006.

69. Lang RM, Badano LP, Mor-Avi V, Afilalo J, Armstrong A, Ernande L, Flachskampf FA, Foster E, Goldstein SA, Kuznetsova T, Lancellotti P, Muraru D, Picard MH, Rietzschel ER, Rudski L, Spencer KT, Tsang W, Voigt JU. Recommendations for cardiac chamber quantification by echocardiography in adults: an update from the American Society of Echocardiography and the European Association of Cardiovascular Imaging. J Am Soc Echocardiogr. 2015;28(1):1-39. https://doi.org/10.1016/j. echo.2014.10.003.

70. Inglessis I, Shin JT, Lepore JJ, Palacios IF, Zapol WM, Bloch $\mathrm{KD}$, Semigran MJ. Hemodynamic effects of inhaled nitric oxide in right ventricular myocardial infarction and cardiogenic shock. J Am Coll Cardiol. 2004;44(4):793-8. https://doi.org/10.1016/j. jacc.2004.05.047.

71. Olsson KM, Halank M, Egenlauf B, Fistera D, Gall H, Kaehler C, Kortmann K, Kramm T, Lichtblau M, Marra A, Nagel C, Sablotzki A, Seyfarth HJ, Schranz D, Ulrich S, Hoeper MM, Lange TJ. Decompensated right heart failure, intensive care and perioperative management in patients with pulmonary hypertension. Dtsch Med Wochenschr. 2016;141(S01):S42-S4747.

72. Harjola VP, Mebazaa A, Celutkiene J, Bettex D, Bueno H, Chioncel O, Crespo-Leiro MG, Falk V, Filippatos G, Gibbs S, LeiteMoreira A, Lassus J, Masip J, Mueller C, Mullens W, Naeije R, Nordegraaf AV, Parissis J, Riley JP, Ristic A, Rosano G, Rudiger A, Ruschitzka F, Seferovic P, Sztrymf B, Vieillard-Baron A, Yilmaz MB, Konstantinides S. Contemporary management of acute right ventricular failure: a statement from the Heart Failure Association and the Working Group on Pulmonary Circulation and Right Ventricular Function of the European Society of Cardiology. Eur J Heart Fail. 2016;18(3):226-41. https://doi. org/10.1002/ejhf.478.

73. Habicher M, Zajonz T, Heringlake M, Boning A, Treskatsch S, Schirmer U, Markewitz A, Sander M. S3 guidelines on intensive medical care of cardiac surgery patients: hemodynamic monitoring and cardiovascular system-an update. Anaesthesist. 2018. https://doi.org/10.1007/s00101-018-0433-6.

74. Ponikowski P, Voors AA, Anker SD, Bueno H, Cleland JGF, Coats AJS, Falk V, Gonzalez-Juanatey JR, Harjola VP, Jankowska EA, Jessup M, Linde C, Nihoyannopoulos P, Parissis JT, Pieske B, Riley JP, Rosano GMC, Ruilope LM, Ruschitzka F, Rutten FH, van der Meer P. 2016 ESC Guidelines for the Diagnosis and
Treatment of Acute and Chronic Heart Failure. Rev Esp Cardiol. 2016;69(12):1167. https://doi.org/10.1016/j.rec.2016.11.005.

75. Gudmundsson P, Rydberg E, Winter R, Willenheimer R. Visually estimated left ventricular ejection fraction by echocardiography is closely correlated with formal quantitative methods. Int J Cardiol. 2005;101(2):209-12. https://doi.org/10.1016/j.ijcard.2004.03.027.

76. Prada G, Fritz VA, Restrepo-Holguín M, Guru PK, Díaz-Gómez JL. Focused cardiac ultrasonography for left ventricular systolic function. N Engl J Med. 2019;381(21):e36. https://doi. org/10.1056/NEJMvcm1802841.

77. Ponikowski P, Voors AA, Anker SD, Bueno H, Cleland JG, Coats AJ, Falk V, Gonzalez-Juanatey JR, Harjola VP, Jankowska EA, Jessup M, Linde C, Nihoyannopoulos P, Parissis JT, Pieske B, Riley JP, Rosano GM, Ruilope LM, Ruschitzka F, Rutten FH, van der Meer P, Authors/Task Force M, Document R. 2016 ESC Guidelines for the diagnosis and treatment of acute and chronic heart failure: The Task Force for the diagnosis and treatment of acute and chronic heart failure of the European Society of Cardiology (ESC). Developed with the special contribution. Eur J Heart Fail. 2016;18(8):891-975. https://doi.org/10.1002/ ejhf.592.

78. Nagueh SF, Smiseth OA, Appleton CP, Byrd BF 3rd, Dokainish H, Edvardsen T, Flachskampf FA, Gillebert TC, Klein AL, Lancellotti P, Marino P, Oh JK, Popescu BA, Waggoner AD. Recommendations for the evaluation of left ventricular diastolic function by echocardiography: an update from the American Society of Echocardiography and the European Association of Cardiovascular Imaging. J Am Soc Echocardiogr. 2016;29(4):277-314. https ://doi.org/10.1016/j.echo.2016.01.011.

79. Pieske B, Tschöpe C, de Boer RA, Fraser AG, Anker SD, Donal E, Edelmann F, Fu M, Guazzi M, Lam CSP, Lancelotti P, Melenovsky V, Morris DA, Nagel E, Pieske-Kraigher E, Ponikowski P, Solomon SD, Vasan RS, Rutten FH, Voors AA, Ruschitzka F, Paulus WJ, Seferovic P, Filippatos G. How to diagnose heart failure with preserved ejection fraction: the HFA-PEFF diagnostic algorithm: a consensus recommendation from the Heart Failure Association (HFA) of the European Society of Cardiology (ESC). Eur Heart J. 2019;40(40):3297-317. https://doi.org/10.1093/eurhe artj/ehz641.

80. Mancia G, Fagard R, Narkiewicz K, Redon J, Zanchetti A, Böhm M, Christiaens T, Cifkova R, De Backer G, Dominiczak A, Galderisi M, Grobbee DE, Jaarsma T, Kirchhof P, Kjeldsen SE, Laurent S, Manolis AJ, Nilsson PM, Ruilope LM, Schmieder RE, Sirnes PA, Sleight P, Viigimaa M, Waeber B, Zannad F, Redon J. 2013 ESH/ESC guidelines for the management of arterial hypertension: the Task Force for the Management of Arterial Hypertension of the European Society of Hypertension (ESH) and of the European Society of Crdiology (ESC). Eur Heart J. 2013;34(28):2159-219. https://doi.org/10.3109/08037 051.2013.812549.

81. DGAI (2017) Intensivmedizinische Versorgung herzchirurgischer Patienten - Hämodynamisches Monitoring und Herz-Kreislauf. https://www.awmf.org/leitlinien/detail/11/001-016.html. Accessed 09 July 2018

82. Leischik R, Dworrak B, Sanchis-Gomar F, Lucia A, Buck T, Erbel R. Echocardiographic assessment of myocardial ischemia. Ann Transl Med. 2016;4(13):259. https://doi.org/10.21037/ atm.2016.07.06.

83. Baumgartner H, Hung J, Bermejo J, Chambers JB, Evangelista A, Griffin BP, Iung B, Otto CM, Pellikka PA, Quiñones M. Echocardiographic assessment of valve stenosis: EAE/ASE recommendations for clinical practice. J Am Soc Echocardiogr. 2009;22(1):123. https://doi.org/10.1016/j.echo.2008.11.029quiz 101-102.

84. Lancellotti P, Tribouilloy C, Hagendorff A, Moura L, Popescu BA, Agricola E, Monin J-L, Pierard LA, Badano L, Zamorano JL. European Association of Echocardiography recommendations for 
the assessment of valvular regurgitation. Part 1: aortic and pulmonary regurgitation (native valve disease). Eur J Echocardiogr: J Work Group Echocardiogr Eur Soc Cardiol. 2010;11(3):223-44. https://doi.org/10.1093/ejechocard/jeq030.

85. Lancellotti P, Moura L, Pierard LA, Agricola E, Popescu BA, Tribouilloy C, Hagendorff A, Monin J-L, Badano L, Zamorano JL. European Association of Echocardiography recommendations for the assessment of valvular regurgitation. Part 2: mitral and tricuspid regurgitation (native valve disease). Eur J Echocardiogr: J Work Group Echocardiogr Eur Soc Cardiol. 2010;11(4):307-32. https://doi.org/10.1093/ejechocard/jeq031.

86. Blanco P, Aguiar FM, Blaivas M. Rapid ultrasound in shock (RUSH) velocity-time integral: a proposal to expand the RUSH protocol. J Ultrasound Med. 2015;34(9):1691-700. https://doi. org/10.7863/ultra.15.14.08059.

87. Mercado P, Maizel J, Beyls C, Titeca-Beauport D, Joris M, Kon$\operatorname{tar}$ L, Riviere A, Bonef O, Soupison T, Tribouilloy C, de Cagny B, Slama M. Transthoracic echocardiography: an accurate and precise method for estimating cardiac output in the critically ill patient. Crit Care. 2017;21(1):136. https://doi.org/10.1186/s1305 4-017-1737-7.
88. Graeser K, Zemtsovski M, Kofoed KF, Winther-Jensen M, Nilsson JC, Kjaergaard J, Moller-Sorensen H. Comparing methods for cardiac output: intraoperatively doppler-derived cardiac output measured with 3-dimensional echocardiography is not interchangeable with cardiac output by pulmonary catheter thermodilution. Anesth Analg. 2018;127(2):399-407.

89. Jozwiak M, Monnet X, Teboul JL. Less or more hemodynamic monitoring in critically ill patients. Curr Opin Crit Care. 2018;24(4):309-15. https://doi.org/10.1097/MCC.0000000000 000516.

90. Heringlake M, Sander M, Treskatsch S, Brandt S, Schmidt C. Hemodynamic target variables in the intensive care unit. Anaesthesist. 2018. https://doi.org/10.1007/s00101-018-0489-3.

Publisher's Note Springer Nature remains neutral with regard to jurisdictional claims in published maps and institutional affiliations. 